\title{
Tingkat Efisiensi Pemasaran Telur Itik Alabio dan Telur Asin di Kabupaten Hulu Sungai Utara Propinsi Kalimantan Selatan
}

\author{
(Marketing Efficiency Levels Alabio Eggs and Salted Egg in \\ Hulu Sungai Utara Regency Kalimantan Selatan Province)
}

\author{
Mahdalena \\ Program Studi Agribisnis, Sekolah Tinggi Ilmu Pertanian Amuntai \\ mahda26_amuntai@yahoo.com
}

\begin{abstract}
ABSTRAK
Penelitian ini bertujuan untuk mengetahui tingkat efesiensi setiap saluran pemasaran telur itik alabio dan telur asin di Kabupaten Hulu Sungai Utara. Kegiatan penelitian dilaksanakan di Kabupaten Hulu Sungai Utara, pada bulan Agustus -Oktober 2013. Metode yang digunakan adalah metode survei dan wawancara dengan lokasi yang dipilih secara sengaja (purposive sampling). Metode Analisis efisiensi menggunakan rumus Indeks Efisiensi Teknis dan Indeks Efisiensi Ekonomis. Berdasarkan hasil penelitian didapatkan efisiensi pemasaran secara teknis dan secara ekonomis adalah pada saluran III tujuan Palangkaraya dan saluran III tujuan Simpang. Efisiensi pemasaran secara teknis dan secara ekonomis pada pemasaran telur asin adalah saluran II IET < IEE yaitu 2,92<3,8.
\end{abstract}

Kata Kunci: Efisiensi, pemasaran, telur, itik, asin.

\section{ABSTRACT}

This study aims to determine the efficiency level of each marketing channel of alabio duck and salted eggs in Hulu Sungai Utara Regency. The research activity was carried out in Hulu Sungai Utara Regency, in August-October 2013. The method used is survey method and interview with deliberately chosen location (purposive sampling). The efficiency analysis method uses the formula of Technical Efficiency Index and Economic Efficiency Index. Based on the results of the study, it was obtained technically and economically marketing efficiency was in channel III for the purpose of Palangkaraya and channel III for Simpang. Technically and economically marketing efficiency in marketing salted eggs is IET II channel <IEE which is $2.92<3.8$.

Keywords: Efficiency, marketing, eggs, ducks, salted.

\section{PENDAHULUAN}

Pembangunan pertanian ditujukan untuk meningkatkan pendapatan petani dan peran pertanian dalam pembangunan nasional secara keseluruhan. Berbagai kegiatan telah ditempuh pemerintah dalam pembangunan pertanian yang secara garis besar meliputi diversifikasi, intensifikasi, ekstensifikasi dan rehabilitasi. Melalui kegiatan-kegiatan tersebut pertanian dapat meningkat secara cepat (Soekartawi, 2005).

Menurut Soekartawi (1989) Peranan lembaga pemasaran biasanya sesuai dengan kemampuan pembiayaan yang dimiliki, dimana akan melakukan fungsi pemasaran yang berbeda-beda, karena perbedaan inilah biaya dan keuntungan pemasaran menjadi berbeda disetiap lembaga pemasaran.
Mubyarto (1989) mendefinisikan pemasaran sebagai suatu kegiatan ekonomi yang berfungsi untuk menyampaikan barang dan jasa dari produsen ke konsumen. Kurangnya perhatian terhadap permasalahan dalam pemasaran akan menimbulkan efisiensi pemasaran yang rendah. Menurut Mubyarto (1989), efisiensi pemasaran merupakan perbandinganantara output dan input dari pemasaran. Output dapat berupa kepuasan konsumen dan input merupakan masukan yang digunakan dalam proses pemasaran. Sedangkan menurut Daniel (2002), sistem pemasaran akan dikatakan efisien apabila: mampu menyampaikan hasil pertanian dari produsen ke konsumen dengan biaya serendah-rendahnya dan pembagian yang adil dari keseluruhan harga yang dibayar oleh konsumen akhir kepada 
semua pihak yang terlibat dalam pemasaran.

Biaya usaha ternak itik petelur jumlahnya semakin besar karena harga pakan yang tinggi yaitu yang disebabkan kurangnya kesediaan pakan ternak seperti paya, dedak dan lain-lain. (pengamatan peneliti). Untuk memberikan nilai tambah terhadap telur itik Alabio, telur itik mentah dapat diolah menjadi telur asin. Dengan melihat kondisi pendapatan peternak dan pemasaran telur itik alabio tersebut, maka tujuan penelitian ini adalah mengetahui tingkat efesiensi setiap saluran pemasaran telur itik alabio dan telur asin di Kabupaten Hulu Sungai Utara.

\section{METODE PENELITIAN}

Kegiatan penelitian dilaksanakan di Kabupaten Hulu Sungai Utara, pada bulan Agustus -Oktober 2013, dengan kegiatan meliputi persiapan, pengumpulan, pengolahan dan analisis data serta pembuatan laporan hasil penelitian.

Data data yang digunakan dalam penelitian ini terdiri dari data primer dan data sekunder. Data primer diperoleh dari para peternak itik alabio yang memproduksi telur dan pengolah telur asin di Kabupaten Hulu Sungai Utara serta para pedagang telur itik dan telur asin yang terkait. Data tersebut diperoleh melalui wawancara terhadap responden (peternak itik yang menjual telur dan pedagang telur itik alabio) dengan menggunakan alat bantu kuisioner. Data Sekunder, data ini diperoleh dari berbagai referensi yang releven dengan masalah yang sedang diteliti seperti Laporan Tahunan kabupaten Hulu Sungai Utara, Dinas Peternakan Kabupaten Hulu Sungai Utara, Badan Pusat Statistik, dan sebagainya serta jurnal dan hasil penelitian yang berkaitan.

Metode analisis data yang digunakan beberapa metode yaitu analisis data secara kualitatif dengan tabulasi serta analisis data kuantitatif dengan pengujian secara statistik. Alat bantu yang digunakan untuk menganalisis data dalam penelitian ini yaitu kalkulator dan software Microsoft Office Excel.

Efesiensi teknis dan ekonomis dapat dihitung dengan angka-angka indeks dengan rumus sebagai berikut (Kusworo dalam Siregar, 2006):

$$
\begin{aligned}
& \text { IET }=\frac{\text { Total Biaya Pemasaran }}{\text { Jarak }(\mathrm{km})} \\
& \text { IEE }=\frac{\text { Total Keuntungan }}{\text { Total Biaya Pemasaran }}
\end{aligned}
$$

Bila perhitungan nilai indeks efesiensi teknis lebih kecil dari nilai indeks efesiensi ekonomis (IET < IEE) maka sistem pemasaran telur itik alabio dapat dikatakan efesien.

\section{HASIL DAN PEMBAHASAN}

\section{Karakteristik Peternak/Produsen Telur Itik Alabio}

Umur. Dari hasil penelitian usia peternak/produser telur itik Alabio di Kabupaten Hulu Sungai Utara berkisar antara 31 - 60 tahun. pada kelompok umur $41-50$ tahun sebanyak 63 orang atau $84 \%$, kelompok umur 31-40 tahun sebanayak 8 orang atau $10,7 \%$ dan kelompok umur 51 60 tahun sebanyak 4 orang atau 5,3\%.

Tingkat Pendidikan .Dari seluruh responden peternak/produsen telur itik Alabio di Kabupaten Hulu Sungai Utara yang tamat $\mathrm{SD} /$ sederajat sebanyak 51 orang atau $68 \%$, tamat SMP/sederajat sebanyak 23 orang atau $30,7 \%$ dan SMA/sederajat sebanyak 1 orang atau $1,3 \%$.

\section{Saluran dan Lembaga Pemasaran Telur Itik Alabio di Kabupaten Hulu Sungai Utara}

Secara sistematis kegiatan pemasaran telur itik Alabio yang terjadi beraneka ragam. Berdasarkan hasil penelitian, menunjukan bahwa terdapat tiga pola saluran pemasaran yang terjadi, yaitu: 
1. Saluran I

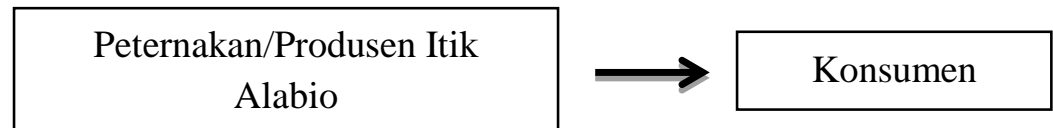

2. Saluran II

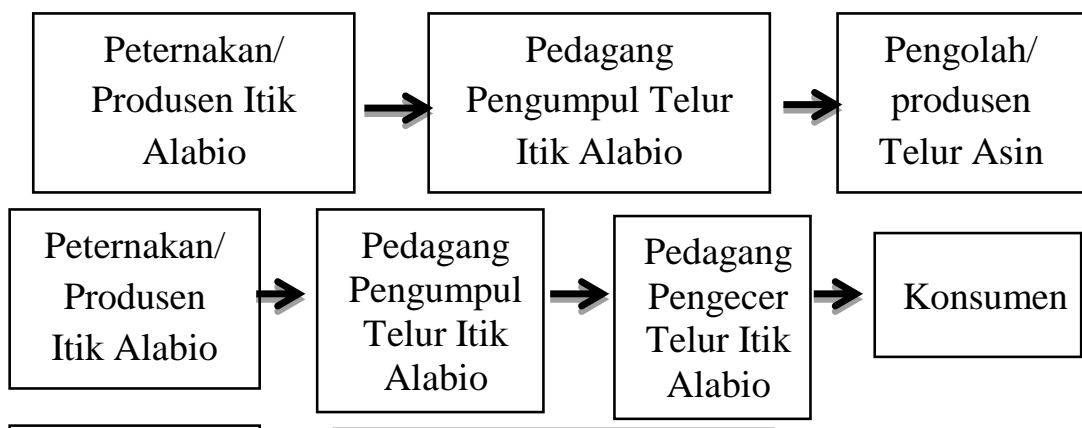

3. Saluran III

\begin{tabular}{|c|c|c|}
$\begin{array}{c}\text { Peternakan/ } \\
\text { Produsen } \\
\text { Itik Alabio }\end{array}$ \\
Pedagang \\
$\begin{array}{c}\text { Pengumpul/Pengecer } \\
\text { Teluri Itik Alabio }\end{array}$
\end{tabular}$\longrightarrow$ Konsumen

\section{Saluran dan Lembaga Pemasaran Telur Asin di Kabupaten Hulu Sungai Utara}

1. Saluran I

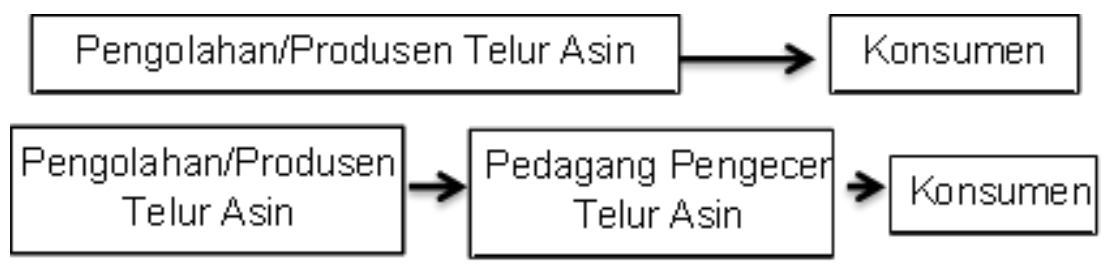

Efiseinsi Pemasaran Telur Itik Alabio

Sisstem pemasaran telur itik Alabio pada masing-masing saluran dikatakan efisien bila perhitungan nilai indeks efisiensi teknis (IET) lebih kecil dari nilai indeks efisiensi ekonomis (IEE). Dari hasil penelitian saluran pemasaran yang paling efisien adalah saluran III tujuan Simpang $0,03<35,36$ dimana nilai IEE itu paling besar walaupun IET tidak palinng kecil dan Saluran III tujuan Palangkaraya 0,02 < 28,63dimana nilai IET paling kecil walaupun nilai IEE tidak paling besar. Akan tetapi keduanya paling efisien.

\section{Efiseinsi Pemasaran Telur Asin}

Secara teknis pada saluran II lebih efisien dari saluran I karena saluran II dengan IET 2,92 artinya setiap $1 \mathrm{Km}$ jarak hanya diperlukan biaya 2,92 rupiah. Sedangkan pada saluran I dengan IET 22,50 artinya setiap $1 \mathrm{Km}$ jarak akan diperlukan biaya 22,50. Maka biaya yang diperlukan lebih kecil terhadap jarak yang jauh dikatakan efisien secara teknis.

Secara ekonomis pada saluran II lebih efisien dari saluran I karena saluran II dengan IEE 3,8 artinya setiap satu rupiah biaya yang dikeluar 3,8 rupiah. Sedangkan pada saluran I dengan IEE 2,11 artinya setiap satu rupiah biaya yang dikeluarkan hanya memberi keuntungan 2,11 rupiah. Maka Keuntungan yang lebih besar terhadap biaya yang dikeluarkan dapat dikatakan efisien.

\section{KESIMPULAN}

Efisiensi secara teknis pada saluran pemasaran telur itik Alabio adalah pada saluran III tujuan Palangkaraya dengan IET $=0,02$ dan efisensi secara ekonomis pada saluran III tujuan Simpang dengan IEE $=35,36$. Efisiensi pemasaran seca teknis dan secara ekonomis adalah pada saluran III tujuan Palangkaraya dan saluran III tujuan Simpang. Efisiensi pemasaran secara teknis 
dan secara ekonomis pada pemasaran telur asin adlaah saluran II IET < IEE yaitu $2,92<3,8$.

\section{DAFTAR PUSTAKA}

Daniel, M. 2002. Pengantar Ekonomi Pertanian. Bumi Aksara. Jakarta.

Mubyarto. 1989. Pengantar Ekonomi Pertanian. LP3ES. Jakarta.

Kasim, A. Syarifuddin. Petunjuk Praktis Menghitung Keuntungan dan Pendapatan Petani. Fakultas Pertanian UNLAM. Banjarbaru. 1995.

Siregar, V. 2006. Analisis Pemasaran Pisang Kepok (Musa.Sp) di Kabupaten Banjar Propinsi Kalimantan Selatan. Laporan Tesis Program Pascasarjana UNLAM Banjarbaru.

Soekartawi. 2005. Agribisnis Teori dan Aplikasinya. PT Raja Grafindo Persada. Jakarta.

Soekartawi. 1989. Prinsif Dasar Ekonomi Pertanian, Teori dan Aplikasinya. Rajawali Pers. 